\title{
Transparent Guideline Methodology Needed
}

Lidal, Ingeborg; Norén, Camilla; Mäkelä, Marjukka

Published in:

Anesthesiology

Publication date:

2013

Document version

Publisher's PDF, also known as Version of record

Citation for published version (APA):

Lidal, I., Norén, C., \& Mäkelä, M. (2013). Transparent Guideline Methodology Needed. Anesthesiology, 119(3), 739. 
clinical trial of mechanical bowel preparation in elective colonic resection. Br J Surg 2007; 94:689-95

5. Seiler CM, Deckert A, Diener MK, Knaebel HP, Weigand MA, Victor N, Büchler MW: Midline versus transverse incision in major abdominal surgery: A randomized, double-blind equivalence trial (POVATI: ISRCTN60734227). Ann Surg 2009; 249:913-20

(Accepted for publication June 11, 2013.)

\section{Transparent Guideline Methodology Needed}

\section{To the Editor:}

As part of learning at the Nordic Workshop of Evidencebased Medicine, we have read with interest the practice guidelines for central venous access, published in your Journal in 2012. ${ }^{1}$ We appraised the quality of this guideline using the checklist developed by The Evidence-Based Medicine Working Group. ${ }^{2}$ Similar criteria for guideline quality have been suggested elsewhere. ${ }^{3}$ Our conclusion was that this much needed guideline is currently unclear about several aspects of the methodology used in developing the recommendations. This means potential users cannot be certain that the recommendations are based on best currently available evidence.

Our concerns are in two main categories: the rigor of development, including methodology of searching, evaluating, and combining the evidence; and editorial independence, including funding and possible conflicts of interest. The methodological issues that we would like to see clarified in the guideline are:

1. Searches for literature: details of search strategies and databases used, including the search terms and strategies used in different databases;

2. Criteria for selecting the evidence: inclusion and exclusion criteria for publications found through the searches;

3. Process of selecting the evidence: number of persons independently applying the criteria at each step of selection and ways of solving disagreement;

4. Process and criteria of appraising the quality of studies for inclusion;

5. Methods used for synthesizing the evidence;

6. Results of meta-analyses (including tests for heterogeneity);

Funding was provided by the Norwegian Knowledge Centre for Health Services (NOKC), Oslo, Norway; Vestfold Hospital Trust (Tonsberg, Norway); and National Institute for Health and Welfare (THL), Helsinki, Finland.

$\dagger$ Available at: www.anesthesiology.org. Accessed May 29, 2013.

$\ddagger$ Available at: www.cdc.gov/hicpac/guidelineMethod/guidelineMethod.html. Accessed May 29, 2013.
7. A statement of conflicts of interest for the authors; and

8. Sources of financial and other support for developing the guideline.

The searches may have missed relevant information. The authors report their searches covered a period from 1968 to 2011, identifying over 2,000 citations. When we made a PubMed search until the end of 2011 using "central venous catheter" as the search term, we found 12,453 references; adding "infection" retained 4,729 of these; and adding "coated" resulted in 128 studies, including a cohort study of catheters coated with antibiotics published in $2011 .^{4}$ This study shows such catheters significantly decreased infections "in a manner that was independent and complementary to the infection control precautions." In the paragraph on Recommendations for Use of Catheters Containing Antimicrobial Agents, the guideline has no references. A clear description of the search strategies could explain such a discrepancy.

The concept of "evidence linkage" is rather central for the methodology but not quite fully explained in the methods. Does it mean "a statement regarding potential relationships between clinical interventions and outcomes" (as in appendix 5)?

In reporting the results, we would appreciate separating the recommendations based on published scientific evidence and opinion-based evidence. Reading the guideline, it was first unclear to us whether the letters (e.g., Category B2 evidence) referred to scientific evidence or opinion-based evidence. Getting to the footnote of appendix 5, it seems the categories refer to scientific evidence only. It would be interesting to learn whether the guideline group for the next version could consider using a more widely used grading system, such as the GRADE (The Grading of Recommendations Assessment, Development and Evaluation). ${ }^{5}$

It may be that we have missed where the authors have referred to the methods used, although we did our best to study the publication and the Supplemental Digital Content carefully. We also searched the website of this Journal $\dagger$ to make sure we did not miss any information on guideline methodology. In many guidelines, for example in a recent one on the prevention of intravascular catheter-related infections ${ }^{6}$ the methodology is provided on an external site. $\neq$

Finally, we would have appreciated seeing the conflict of interest statements for all authors, and a declaration of how this undoubtedly work-intensive process has been funded.

Making the evidence more transparent would be helpful to guideline users. Our suggestions are anchored in principles of evidence-based medicine. Our aim with this letter is to encourage the authors to provide information which could increase our confidence in the guideline and thus promote its application in practice.

We hope that this important guideline will be updated within a couple of years, and that the American Society of Anesthesiologists Task Force on Central Venous Access will consider adding the necessary methodological information in their guideline. 
Ingeborg Lidal, M.D., Ph.D., Camilla Norén, R.N., Marjukka Mäkelä, M.D., Ph.D., M.Sc.(ClinEpi).* *Finohta (Finnish Office for Health Technology Assessment) at THL (National Institute for Health and Welfare), Helsinki, Finland.marjukka.makela@thl.fi

\section{References}

1. Practice guidelines for central venous access. A report by the American Society of Anesthesiologists Task Force on Central Venous Access. ANESTHESIOLOGY 2012; 116:539-73

2. Guyatt G, Rennie D, O'Meade M, Cook DJ: Users' Guides to the Medical Literature: A Manual for Evidence-Based Clinical Practice, 2nd edition. New York, JAMA Evidence, McGrawHill Education, 2008

3. Brouwers M, Kho ME, Browman GP, Burgers JS, Cluzeau F, Feder G, Fervers B, Graham ID, Grimshaw J, Hanna S, Littlejohns P, Makarski J, Zitzelsberger L; For the AGREE Next Steps Consortium. AGREE II: Advancing guideline development, reporting and evaluation in healthcare. Can Med Assoc J 2010; 182:E839-842

4. Ramos ER, Reitzel R, Jiang Y, Hachem RY, Chaftari AM, Chemaly RF, Hackett B, Pravinkumar SE, Nates J, Tarrand JJ, Raad II: Clinical effectiveness and risk of emerging resistance associated with prolonged use of antibiotic-impregnated catheters: More than 0.5 million catheter days and 7 years of clinical experience. Crit Care Med 2011; 39:245-51

5. Guyatt GH, Oxman AD, Vist GE, Kunz R, Falck-Ytter Y, Alonso-Coello P, Schünemann HJ; GRADE Working Group: GRADE: An emerging consensus on rating quality of evidence and strength of recommendations. BMJ 2008; 336:924-6

6. O'Grady NP, Alexander M, Burns LA, Dellinger EP, Garland J, Heard SO, Lipsett PA, Masur H, Mermel LA, Pearson ML, Raad II, Randolph AG, Rupp ME, Saint S; Healthcare Infection Control Practices Advisory Committee (HICPAC) Guidelines for the prevention of intravascular catheterrelated infections. Clin Infect Dis 2011; 52:e162-93

(Accepted for publication June 11, 2013.)

\section{In Reply:}

We thank Dr. Lidal, Ms. Norén, and Dr. Mäkelä for their comments on the Practice Guidelines for Central Venous Access. ${ }^{1}$ We were quite surprised at a request for more transparency, as the American Society of Anesthesiologists evidence-based process for guideline development is remarkably transparent compared with other published guidelines. Nonetheless, we are delighted to have the opportunity to describe our process.

Regarding our literature search, we agree that information pertaining to search terms and databases used was not specified in the guidelines, although an outline of the general search strategy used in the development of all of our guidelines is readily available. ${ }^{2-4}$ We typically begin with PubMed and expand our search where appropriate (e.g., Cochrane Systematic Review Database, Cochrane Database of Clinical Trials). The search is supplemented by hand searches of reviewed studies and additional citations provided by the task force, consultants, and others. Searches are typically limited to studies reporting original data published in peer-reviewed, English-language journals. Editorials, letters (unless a relevant case is described), and the reporting of meta-analyses conducted by others are excluded. Inclusion and exclusion criteria for literature can be found in the "Focus" section of the guidelines (pages 539-540). By applying these exclusionary criteria, the search protocol easily reduces to the smaller number of appropriate citations indicated in appendix 5 (page 553). Our two methodologists applied these selection criteria, as part of the search and review process. Articles selected were, in turn, verified by means of a reliability assessment involving the entire 12-member task force. Findings from this assessment are described in appendix 5 (page 554).

The process and criteria for appraising the quality of studies for inclusion and methods used for synthesizing evidence are described under the heading "scientific evidence," pages 540-541, and in appendix 5 (pages 553-554). Meta-analytic results, including tests for heterogeneity, are reported in appendix 5 (page 554), table 1 (page 555), and throughout the text in the guidelines.

A statement regarding conflict of interest was not included in the guidelines, although participation in the task force includes completion of a standard conflict of interest form. Those with major conflicts of interest are excluded from the task force. Financial support was provided entirely by the American Society of Anesthesiologists. All physician members of the task force were volunteers, who in total contributed hundreds of work hours in developing the guidelines.

The literature search was very thorough and was guided by the evidence linkage interventions described in appendix 5 (pages 553-554) and the inclusion/exclusion criteria in the "Focus" section. In the document, we specifically reported the highest level of evidence, as described on pages 540-541. All of the literature reviewed for these guidelines is available as supplemental digital content from the journal's website. The reporting format for all of the American Society of Anesthesiologists practice parameters first reports literature-based evidence, followed by opinion-based evidence, and then the recommendations. Evidence, including meta-analytic findings pertinent to the use of catheters containing antimicrobial agents, can be found on pages 542-543. Of further note, the article by Ramos et al. ${ }^{5}$ cited in your letter, while published subsequent to formulation of the guidelines, would not have been included in our evidentiary database because it addressed long-term use of catheters.

As noted in our "Scientific Evidence" section, we rely first on the best scientific evidence available and use opinionbased surveys and other resources to provide guidance for practicality and feasibility purposes. For these guidelines, we conducted formal surveys of 55 expert consultants and 251 practicing physicians to determine appropriateness and practicality of our recommendations, as well as used additional surveys and informal opinion to assess the validity and feasibility of implementing the guidelines. When scientific evidence is unavailable, opinion-based evidence from experts and from our general membership becomes the only formal resource available to provide guidance to the task force. 